\title{
APLICAÇÃO DE TÉCNICAS ELETROQUÍMICAS NO ESTUDO DA DISSOLUÇÃO OXIDATIVA DA COVELITA (CUS) POR THIOBACILLUS FERROOXIDANS
}

\author{
Christiane Medina Teixeira, Ivan Ramires, Oswaldo Garcia Júnior e Antonio Carlos Guastaldi* \\ Instituto de Química, Universidade Estadual Paulista, CP 355, 14801-970 Araraquara - SP
}

Recebido em 26/9/00; aceito em 6/7/01

\begin{abstract}
ELECTROCHEMICAL TECHNIQUES APPLIED TO STUDY THE OXIDATIVE DISSOLUTION OF THE COVELLITE - CuS by THIOBACILLUS FERROOXIDANS. Among the copper sulphides, chalcopyrite $\left(\mathrm{CuFeS}_{2}\right)$, covellite $(\mathrm{CuS})$ and chalcocite $\left(\mathrm{Cu}_{2} \mathrm{~S}\right)$ are the most important source of minerals for copper mining industry. The acknowledge of behaviour of these sulphides related with bacterial leaching process are essential for optimization procedures. Despite of its importance, covellite has not deserved much interest of researchers regarding this matter. In this work it was studied the oxidation of covellite by the chemolithotrophic bacterium Thiobacillus ferrooxidans by using electrochemical techniques, such as open circuit potentials with the time and cyclic voltammetry. The experiments were carried out in acid medium ( $\mathrm{pH} 1.8$ ), containing or not $\mathrm{Fe}^{2+}$ as additional energy source, and in different periods of incubation; chemical controls were run in parallel. The results showed that a sulphur layer is formed spontaneously due the acid attack, covering the sulphide in the initial phase of incubation, blocking the sulphide oxidation. However, the bacterium was capable to oxidize this sulphur layer. In the presence of $\mathrm{Fe}^{2+}$ as supplemental energy source, the corrosion process was facilitated, because ocurred an indirect oxidation of covellite by $\mathrm{Fe}^{3+}$, which was produced by T. ferrooxidans oxidation of the $\mathrm{Fe}^{2+}$ added in the medium.
\end{abstract}

Keywords: Thiobacillus ferrooxidans; bioleaching; electrochemical techniques.

\section{INTRODUÇÃO}

Devido ao aumento da demanda mundial dos bens minerais, temse verificado um progressivo esgotamento das reservas contendo alto teores dos metais de interesse econômico. Dessa forma, torna-se importante o desenvolvimento de métodos alternativos para o tratamento de minérios contendo baixos teores desses materiais. Assim o uso de técnicas hidrometalúrgicas vem merecendo crescente atenção dos técnicos e empresários do setor mínero-metalúrgico.

A Hidrometalurgia consiste na utilização de soluções ácidas ou básicas para o tratamento dos minérios e a recuperação desses metais de interesse. Entre os processos hidrometalúrgicos, há um processo biotecnológico denominado Biohidrometalurgia ou lixiviação bacteriana, que utiliza microrganismos capazes de promoverem a solubilização de metais pela oxidação de sulfetos metálicos. Esta técnica é reconhecida atualmente como uma alternativa ou processo complementar, para a recuperação e obtenção de metais de minérios de teores reduzidos. Estima-se um mercado de cerca de 10 bilhões de dólares para esse tipo de processo ${ }^{1}$.

A lixiviação bacteriana é atualmente aplicada em escala industrial para recuperação de metais como cobre, urânio e ouro ${ }^{2}$, em países como: E.U.A., Rússia, Chile, Espanha, Canadá, África do Sul, Australia entre outros ${ }^{3}$. A lixiviação bacteriana do cobre tem sido muito estudada em minerais sulfetados. Apesar da calcopirita $\left(\mathrm{CuFeS}_{2}\right)$ ser o mineral sulfetado de cobre mais abundante na natureza, existem outros dois minerais sulfetados também importantes economicamente, a calcocita $\left(\mathrm{Cu}_{2} \mathrm{~S}\right)$ e a covelita $(\mathrm{CuS})$.

A principal bactéria envolvida neste processo é o T. ferrooxidans, uma espécie acidofílica que apresenta como metabolismo central a oxidação de sulfetos metálicos, enxofre reduzido e íon $\mathrm{Fe}^{2+}$, como forma de obtenção de energia para o seu metabolismo.

\footnotetext{
* e-mail: guastald@iq.unesp.br
}

O processo de lixiviação bacteriana é um fenômeno químico, no entanto, também pode ser considerado como um processo eletroquímico, pois ocorre transferência de elétrons do mineral para o microrganismo; portanto a biolixiviação nada mais é que um processo de corrosão.

Muitos estudos já foram feitos para se compreender o mecanismo da lixiviação de metais por bactérias ${ }^{4-10}$, no entanto, o mecanismo eletroquímico dos processos de biolixiviação, principalmente a lixiviação do cobre, pouco se conhece. O entendimento destes mecanismos utilizando-se técnicas eletroquímicas, é de fundamental importância para orientar os estudos de otimização dos processos de recuperação de metais, principalmente em escala industrial.

\section{PARTE EXPERIMENTAL}

\section{Amostra mineral}

O mineral utilizado neste trabalho foi o sulfeto metálico natural covelita (CuS), "grau de pesquisa", fornecido pela Ward's Natural Science Establishment (Rochester, New York).

Para as análises metalográficas e ensaios eletroquímicos, o mineral natural foi preparado em cubos de aproximadamente $2,5 \mathrm{~cm}^{2}$ de área por $0,5 \mathrm{~cm}$ de espessura e polidos com lixas de 320 a 1000 mesh, a fim de minimizar irregularidades em sua superfície. A análise da composição química utilizou o mineral em pó, triturado empregando-se um moinho de bolas; e para os ensaios de difratometria de raios $\mathrm{X}$ utilizou-se tanto amostras na forma de cubos quanto na forma de pó.

\section{Microrganismo}

O microrganismo utilizado foi o T. ferrooxidans-LR, isolado da lixívia ácida de minério de urânio da mina de Lagoa Real- Bahia, Brasil $^{11}$. 


\section{Meio de cultura}

Para a manutenção periódica (repiques mensais) bem como para o preparo da suspensão celular de $T$. ferrooxidans, foi utilizado o meio de cultura "T\&K"12 (solução A + solução B) com algumas modificações ${ }^{7}$. A solução A do referido meio é composta por: 0,625 $\mathrm{g} / \mathrm{L}\left(\mathrm{NH}_{4}\right)_{2} \mathrm{SO}_{4} ; 0,625 \mathrm{~g} / \mathrm{L} \mathrm{K}_{2} \mathrm{HPO}_{4} ; 0,625 \mathrm{~g} / \mathrm{L} \mathrm{MgSO} \mathrm{Mg}_{4} \cdot 7 \mathrm{H}_{2} \mathrm{O}$ a pH 1,8 . A solução $\mathrm{B}$ é composta pela fonte de energia para o microrganismo e contém: $166,5 \mathrm{~g} / \mathrm{L} \mathrm{FeSO}_{4} \cdot 7 \mathrm{H}_{2} \mathrm{O}$ a pH 1,8. A solução A foi esterilizada por 20 minutos a $120^{\circ} \mathrm{C}$ em autoclave e a solução B por filtração em membrana $(0,45 \mathrm{~mm}$ de diâmetro de poro). No momento do uso, as soluções A e B foram misturadas na proporção de 4:1, respectivamente.

\section{Preparo da suspensão celular}

O T. ferrooxidans-LR foi cultivado em meio "T\&K" até a fase estacionária de crescimento (2-3 dias) à temperatura de $30^{\circ} \mathrm{C}$ em mesa agitadora com rotação de $150 \mathrm{rpm}$. Após o crescimento, a suspensão foi filtrada em papel de filtro Whatman $n^{\circ} 41$ de filtragem rápida, para retirada dos resíduos do meio e a seguir centrifugada a $10.000 \mathrm{rpm}$ por 30 minutos sob refrigeração. A suspensão celular assim coletada foi lavada três vezes em solução $\mathrm{H}_{2} \mathrm{SO}_{4} 0,01 \mathrm{Mol}$ $\mathrm{L}^{-1}$ e finalmente suspensa em $\mathrm{H}_{2} \mathrm{SO}_{4} 0,01 \mathrm{Mol} \mathrm{L}^{-1}$. O número de células $\left(7,5 \times 10^{8}\right.$ células $\left.\mathrm{mL}^{-1}\right)$ foi obtido pela leitura da absorbância da suspensão em $\mathrm{OD}_{500}{ }^{13}$.

\section{Caracterização da amostra}

A composição química da amostra foi determinada utilizandose espectrometria de emissão atômica em plasma de acoplamento indutivo- ICP-AES para ferro e silício, volumetria com tiossulfato de sódio para cobre e gravimetria com $\mathrm{BaCl}_{2}$ para enxofre total.

Para a caracterização de outros minerais presentes na amostra original utilizou-se a técnica de difração de raios X- DRX, empregando-se um difratômetro SIEMENS D5000 na montagem de BraggBrentano, utilizando-se radiação de $\mathrm{Cu}$ (ka1), com varredura angular entre $20^{\circ}$ e $80^{\circ}$, com passo de $0,05^{\circ}$ e tempo de leitura de $1,0 \mathrm{~s}$ para a amostra na forma de cubo e passo de $0,02^{\circ}$ e tempo de leitura de 2,0 s para a amostra em pó. A identificação dos minerais foi realizada utilizando-se fichas padrões de difração do Joint Committee on Powder Diffraction Standards-JCPDS.

Para a análise metalográfica foi utilizado o método de microscopia eletrônica de varredura- MEV, com sistema de micro-sonda acoplado, permitindo mapeamento de elementos e análises localizadas semiquantitativas e qualitativas. Neste trabalho utilizou-se um microscópio eletrônico de varredura do tipo JEOL-JSM, modelo T-330 A, acoplado a um analisador de espectroscopia por dispersão de energia de raios X-EDX e a uma câmera fotográfica.

\section{Ensaios eletroquímicos}

Os ensaios eletroquímicos foram realizados para amostras incubadas em quatro diferentes períodos 0, 2, 7 e 14 dias. Estas foram preparadas na forma de cubos e colocadas em frascos Erlenmeyer $500 \mathrm{~mL}$ contendo $200 \mathrm{~mL}$ da solução A do meio "T\&K”. Os frascos foram incubados em mesa agitadora $(150 \mathrm{rpm})$ por um período de tempo de 2 dias à temperatura controlada de $30^{\circ} \mathrm{C}$. A seguir, as amostras foram retiradas da solução e submetidas aos ensaios eletroquímicos de potencial de circuito aberto com o tempo e voltametria cíclica. Após cada ensaio, cada amostra foi novamente polida e incubada durante 7 dias, como no procedimento já descrito, repetindo-se o processo para 14 dias de incubação.
Para a realização desses ensaios as amostras foram incubadas com e sem inóculo microbiano (controle químico) bem como na presença e ausência do íon $\mathrm{Fe}^{2+}$.

Foi utilizada uma célula eletroquímica plana EG \& G PARC composta por três eletrodos: eletrodo de trabalho (mineral), eletrodo de referência (calomelano saturado - $\mathrm{Pt}, \mathrm{Hg} / \mathrm{Hg}_{2} \mathrm{Cl}_{2} / \mathrm{KCl}_{\text {sat }}-\mathrm{ECS}$ ) e eletrodo auxiliar (eletrodo de platina). A área exposta para os ensaios eletroquímicos foi de $1 \mathrm{~cm}^{2}$. A solução eletrolítica foi a solução A do meio "T\&K"

O procedimento experimental dos ensaios de potencial de circuito aberto com o tempo constou, basicamente, da montagem da célula eletrolítica conectada a um potenciostato MQPG-01 interligado a um computador por meio de uma interface MQI12/8PCC.

Os diferentes períodos de incubação foram analisados por um período de tempo de $24 \mathrm{~h}$, em meio aerado, com o objetivo de se estabelecer a região de estabilização de potencial do material e o comportamento do potencial até esta região.

Para os ensaios de voltametria cíclica utilizou-se um potenciostato Solartron modelo 1287 acoplado a um computador. A técnica de voltametria cíclica tem sido utilizada para diagnosticar mecanismos de reações eletroquímicas, para a identificação de espécies presentes em solução e para a análise semiquantitativa de velocidades de reações ${ }^{14}$.

\section{Análise Química da Solução}

O meio de cultura "T\&K" foi analisado quanto ao teor de cobre em solução, para os quatro diferentes ensaios utilizando-se um espectrofotômetro de absorção atômica Perkin Elmer A Analyst 300.

\section{RESULTADOS E DISCUSSÃO}

\section{Caracterização da amostra}

A Tabela 1 apresenta a composição química da amostra original para os elementos que estão em maior concentração no mineral $(\mathrm{Cu}$, $\mathrm{S}, \mathrm{Fe}$ e $\mathrm{Si}$ ).

Tabela 1. Composição química da amostra utilizada no ensaio

\begin{tabular}{cc}
\hline Elemento & $(\%)$ em peso \\
\hline $\mathrm{Cu}$ & 55,50 \\
$\mathrm{Fe}$ & 3,52 \\
$\mathrm{~S}$ & 30,41 \\
$\mathrm{Si}$ & 1,32 \\
\hline
\end{tabular}

A Figura 1 apresenta os difratogramas de raios X para a amostra sólida original em um único pedaço (A) e em pó (B), respectivamente. Identificou-se na amostra os seguintes minerais: sulfeto de cobre$\mathrm{CuS}$ (covelita), pirita-FeS $\mathrm{S}_{2}$ e uma pirita que contém níquel em sua composição-(Fe,Ni) $\mathrm{S}_{2}$. Para amostra em pó identificou-se uma maior quantidade de covelita e ausência de pirita contento níquel, devido a uma maior homogeneidade da amostra em pó e regiões preferênciais desta forma cristalina na amostra cortada. Os resultados da difração de raios X, estão condizentes com a análise química da Tabela 1, pois os elementos $\mathrm{Fe}, \mathrm{Cu}$ e $\mathrm{S}$ identificados nesta análise estão presentes nos difratogramas na forma de sulfetos. O Si não foi detectado nem mesmo na sua forma mais comum, $\mathrm{SiO}_{2}$, pois fases constituintes em frações volumétricas menores que 5\% dificilmente são detectadas, isto é, os picos destas fases se confundem com a radiação de fundo ${ }^{15}$.

A Figura 2-A apresenta a micrografia da superfície da amostra original obtida por microscopia eletrônica de varredura-MEV. Pode- 

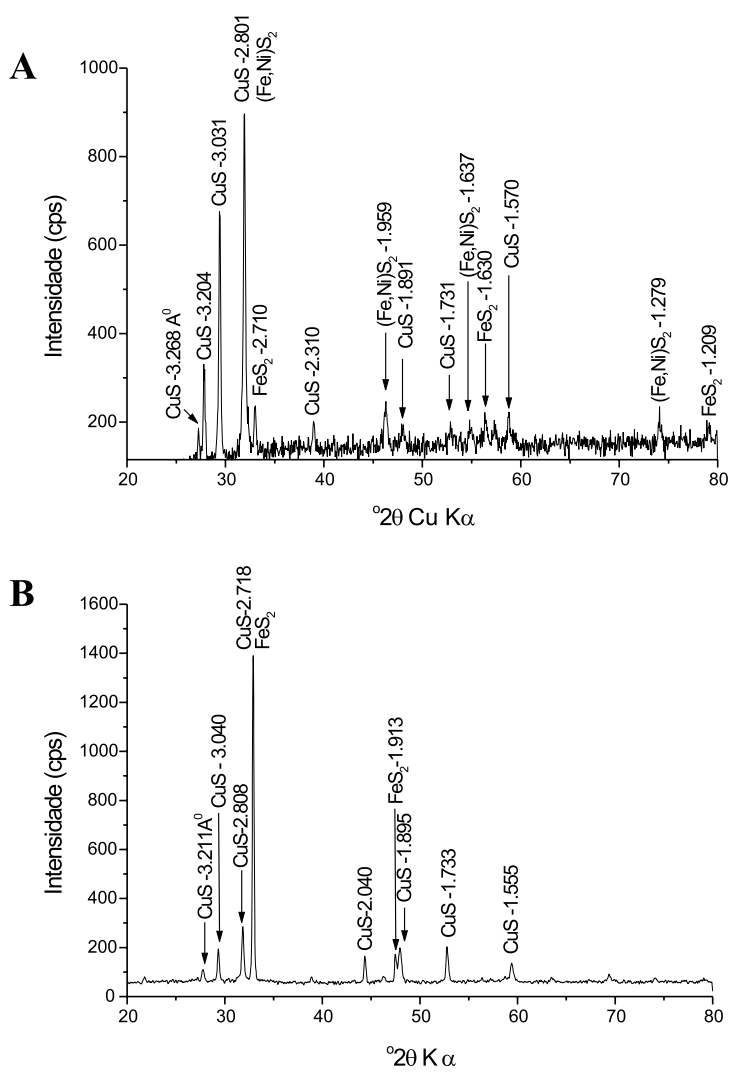

Figura 1. Difratogramas de raios $X$ da amostra original. A. Amostra na forma de cubo. B. amostra em pó.

se observar que a amostra apresenta uma superfície irregular com porosidades, mesmo após todo o processo de polimento. A Figura 2B mostra a análise referente a região da Figura 2-A por espectroscopia por dispersão de energia de raios X-EDX. Nota-se que apenas os picos espectrais característicos dos elementos cobre e enxofre foram identificados por esta técnica. As Figuras 2-C e 2-D mostram o mapeamento elementar para os elementos cobre e enxofre, respectivamente. Analisando-se estas figuras nota-se que a distribuição destes elementos é homogênea em toda a região, coerente com a análise química, pois são os principais constituintes da amostra em estudo.

A Figura 3-A mostra uma região clara na qual procedeu-se uma análise empregando-se EDX, mostrada na Figura 3-B. Identificou os elementos $\mathrm{Cu}, \mathrm{S}$, Si e Fe nesta região em estudo, resultados estes coerentes com a análise química, pois as intensidades relativas dos picos para o $\mathrm{Cu}$ e $\mathrm{S}$, constituintes principais, são proporcionalmente muito maiores do que as intensidades do Si e Fe (Tabela 1). A presença do $\mathrm{Si}$ e do Fe pode ser explicado pelos teores maiores destes elementos, dentro do limite de detecção, em algumas regiões da amostra.

Após a análise de EDX, realizou-se o mapeamento elementar para o ferro e silício mostrados nas Figuras 3-C e 3-D. Nota-se nestas figuras regiões que apresentam maiores concentrações destes elementos (pontos brancos).

\section{Ensaios Eletroquímicos}

\section{Potencial de circuito aberto com o tempo}

A Figura 4-A mostra os gráficos da variação do potencial de circuito aberto com o tempo, para a amostra incubada nos tempos 0 , 2, 7 e 14 dias na solução A do meio "T\&K”, sem microrganismo. De
A
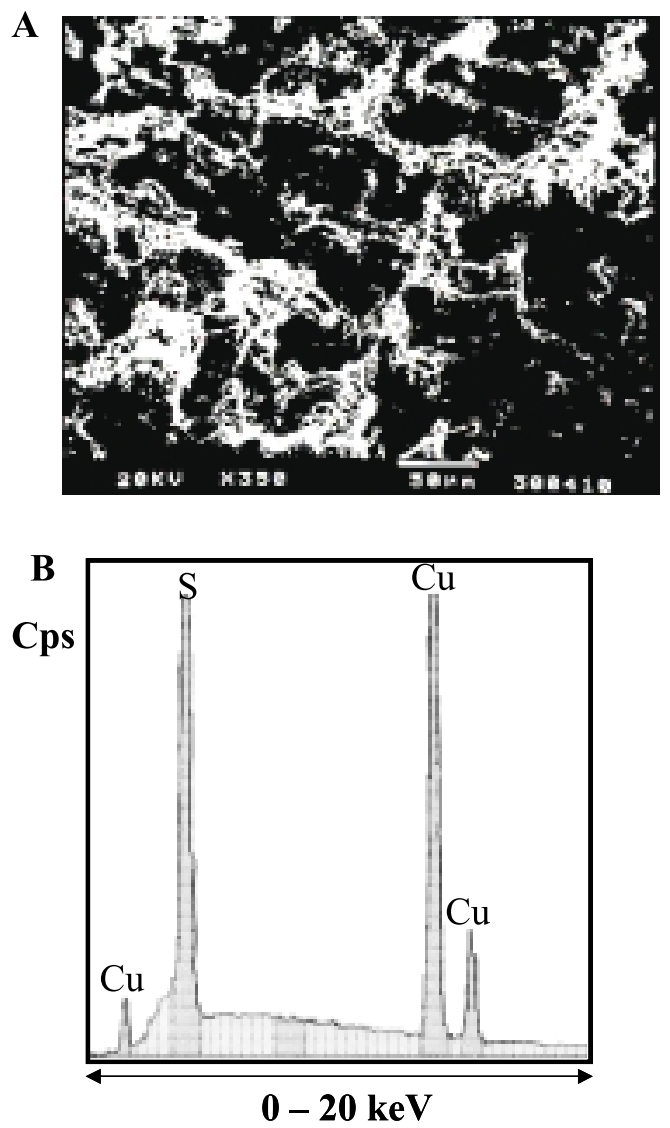

C

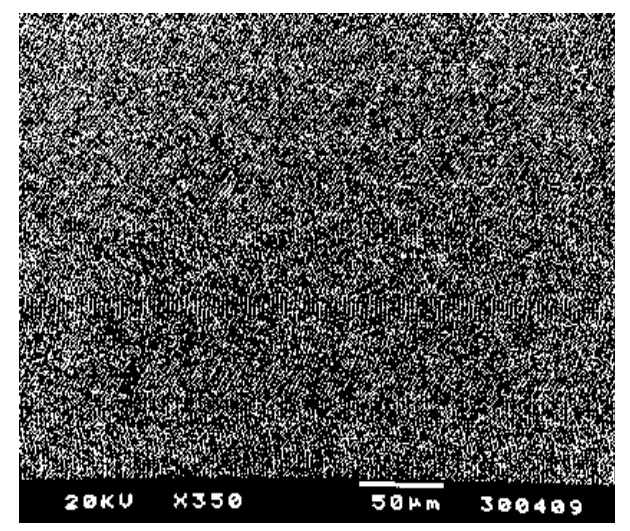

D

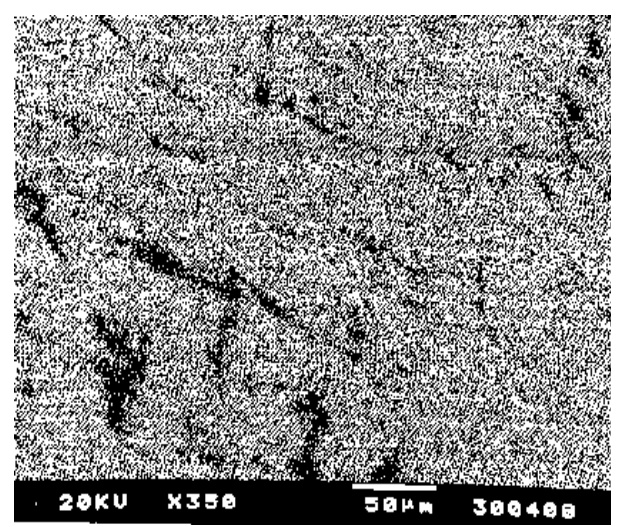

Figura 2. Amostra original. A. Micrografia da superfície. B. EDX. C. Mapeamento elementar do cobre. D. Mapeamento elementar do enxofre. Aumento: 350X. 
A

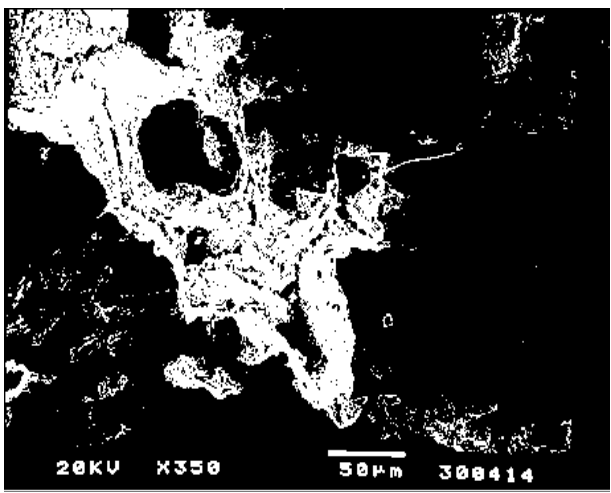

B

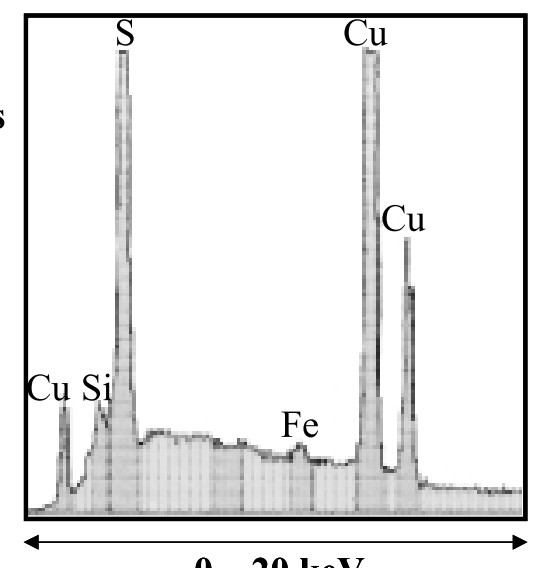

0 - $20 \mathrm{keV}$

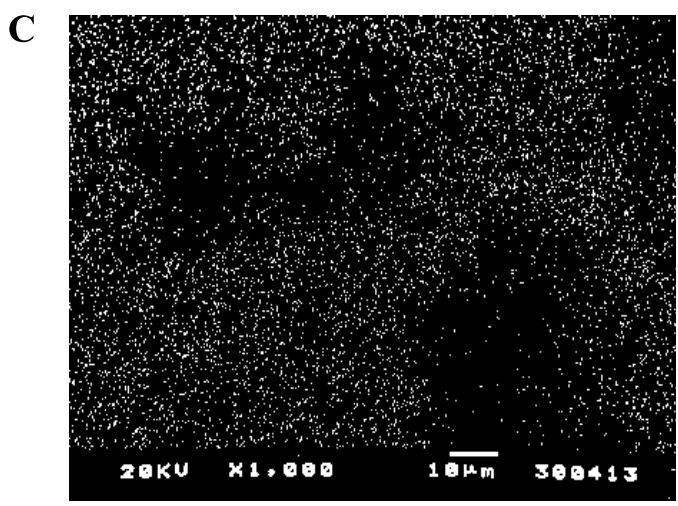

D

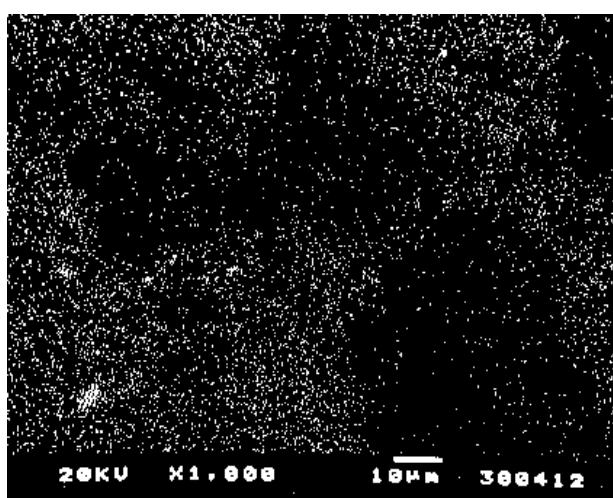

Figura 3. Amostra original. A. Micrografia da superfície. Aumento: 350X. B. EDX. C. Mapeamento elementar do ferro. D. Mapeamento elementar do silício. Aumento: 1000X.
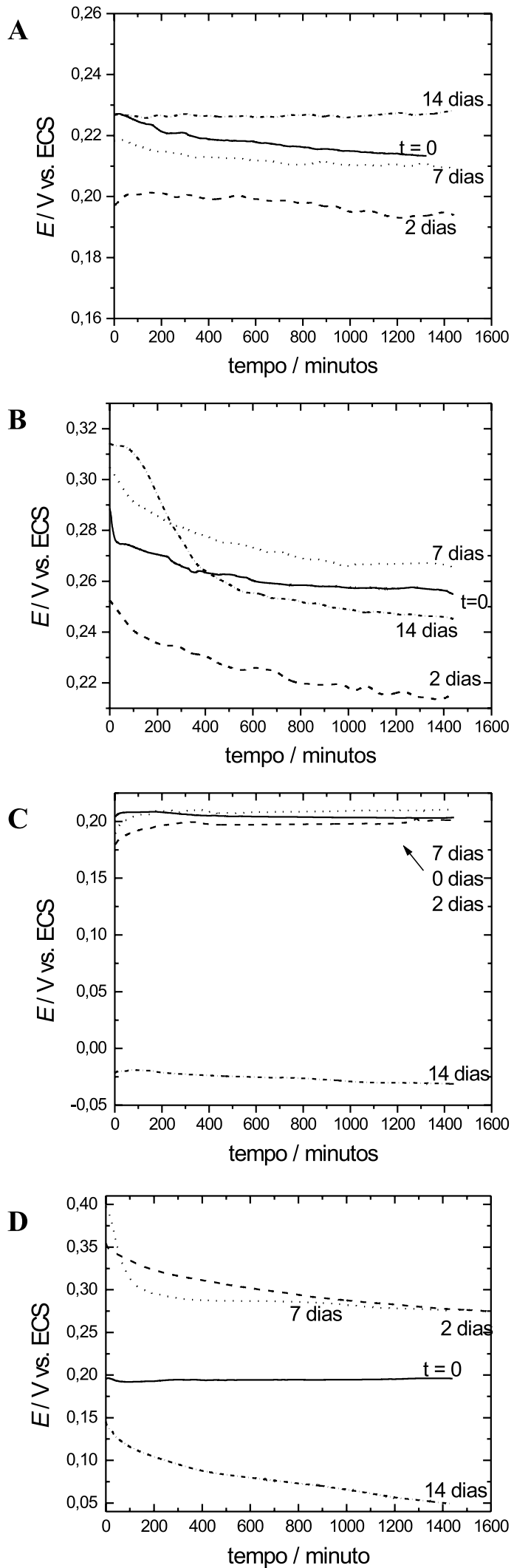

Figura 4. Curvas de potencial de circuito aberto com o tempo para as amostras de covelita em solução eletrolítica, após os tempos de incubação de 0, 2, 7 e 14 dias. Tempo de experimento de 24h. A. Amostra em solução A do meio "T\& K" sem microrganismo. B. Amostra em meio " $T \& K$ " completo, sem microrganismo. C. Amostra em solução A do meio " $T \& K$ " com microrganismo. D. Amostra em meio " $T \& K$ " completo com microrganismo. 
acordo com os resultados obtidos para este ensaio, pode-se observar que não ocorreu uma grande variação dos potenciais, quando comparados os diferentes tempos de incubação. A estabilidade do potencial pode ser devido à formação de uma camada passiva de enxofre elementar sobre a superfície do mineral, devido a dissolução não biológica da covelita. Essa fase cristalina (enxofre) foi comprovada por meio do DRX para a amostra após 7 dias de incubação em solução A do meio "T\&K" sem microrganismo (Figura 5).

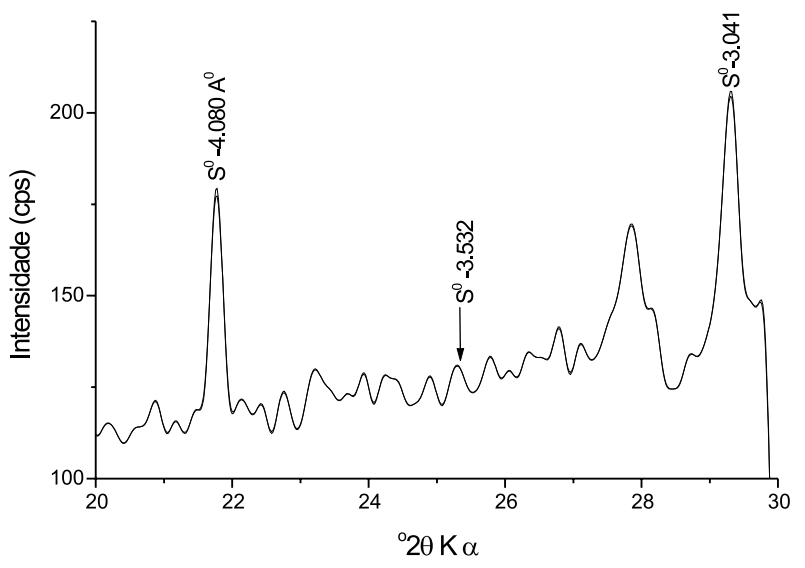

Figura 5. Difratograma de raios X para a amostra na forma de cubo após 7 dias de incubação em solução A do meio " $T \& K$ ”.

A reação 1 apresenta a dissolução não biológica da covelita ${ }^{5}$.

$$
\mathrm{CuS}+1 / 2 \mathrm{O}_{2}+2 \mathrm{H}^{+} \rightarrow \mathrm{Cu}^{2+}+\mathrm{H}_{2} \mathrm{O}+\mathrm{S}^{0}
$$

A Figura 4-B mostra os potenciais de circuito aberto com o tempo para a amostra incubada em meio "T\&K" completo, sem microrganismo, após os tempos de incubação de 0, 2, 7 e 14 dias. De acordo com os resultados apresentados, não ocorreu variação significativa do potencial, comportando-se de forma semelhante aos ensaios apresentados na Figura 4-A. Assim, a adição de $\mathrm{Fe}^{2+}$ não tem atuação significativa sobre a superfície da amostra na ausência de bactéria.

A Figura 4-C apresenta os potenciais de circuito aberto com o tempo para a amostra incubada na solução A do meio "T\&K", com microrganismo, após os tempos de 0, 2, 7 e 14 dias. Os resultados mostraram que após os primeiros 7 dias de incubação, houve uma pequena variação de potencial, em torno de $0,030 \mathrm{~V}$ (ECS), coerente com os resultados obtidos na Figura 4-A, devido à formação de uma camada de enxofre elementar ${ }^{7}$, conforme constatado na Figura 5. No entanto, os resultados de potencial obtidos para a amostra incubada por 14 dias mostraram uma brusca queda de potencial, devido, provavelmente, à oxidação do enxofre elementar pelo microrganismo. Essa oxidação determina a formação de ácido sulfúrico (Reação 2$)^{6}$, conforme constatado pela diminuição dos valores de $\mathrm{pH}$ da solução de trabalho, verificado por medidas experimentais (resultados não mostrados).

$$
\mathrm{S}^{0}+3 / 2 \mathrm{O}_{2}+\mathrm{H}_{2} \mathrm{O} \rightarrow \mathrm{H}_{2} \mathrm{SO}_{4}
$$

A Figura 4-D mostra os potenciais de circuito aberto com o tempo em solução eletrolítica para a amostra incubada no meio "T\&K" completo na presença de microrganismos, após os tempos de incubação de 0, 2, 7 e 14 dias. Os resultados mostraram que após os primeiros 7 dias de incubação, ocorreu um aumento do potencial devido à formação da camada de enxofre e da oxidação biológica do
$\mathrm{Fe}^{2+}$ para $\mathrm{Fe}^{3+}$, o qual pode atuar como um excelente agente oxidante do mineral em estudo ${ }^{10}$. A brusca diminuição do potencial após o $14^{\circ}$ dia, indica que ocorreu um consumo da camada de enxofre elementar pelo microrganismo além da dissolução indireta da covelita pelo $\mathrm{Fe}^{3+}$, produzido pela oxidação biológica do $\mathrm{Fe}^{2+}$.

\section{Voltametria cíclica}

A Figura 6-A, apresenta os voltamogramas cíclicos em solução eletrolítica para a amostra incubada em solução A do meio "T\&K" sem microrganismo, após 0, 2, 7 e 14 dias de incubação. Pode-se observar um pico de oxidação do cobre $\left(\mathrm{A}_{1}\right)$ em potenciais próximos a -0,2 V. Entre 0,3 e $0,4 \mathrm{~V}$ apareceu um pico de oxidação para o enxofre $\left(\mathrm{A}_{2}\right)$ e em potenciais entre $0,9 \mathrm{~V}$ e $1,1 \mathrm{~V}$ o voltamograma apresentou um pico de oxidação do ferro $\left(\mathrm{A}_{3}\right)$.

O motivo do aparecimento do pico $\left(\mathrm{A}_{1}\right)$ de oxidação de cobre, pode estar relacionado com a formação, primeiramente, de um intermediário $\mathrm{Cu}^{+}$nos primeiros momentos de incubação ${ }^{7}$, passando a $\mathrm{Cu}^{2+}$ no potencial acima mencionado. $\mathrm{O}$ pico $\left(\mathrm{A}_{2}\right)$ está relacionado à oxidação do $S^{2-}$ para $S^{0}$, em potenciais próximos a $0,4 \mathrm{~V}$. O pico $\left(\mathrm{A}_{3}\right)$ está relacionado à transformação $\mathrm{Fe}^{2+}$ para $\mathrm{Fe}^{3+}$ presentes no mine$\mathrm{ral}^{16}$. O aparecimento do pico de oxidação do ferro se deu porque a amostra é heterogênea, existindo regiões com maiores concentrações de ferro (Figura 3B).

A parte catódica do voltamograma apresentou apenas um pico relacionado à redução do $\mathrm{S}^{0}$ para $\mathrm{S}^{-2}$, formando $\mathrm{H}_{2} \mathrm{~S}\left(\mathrm{~B}_{1}\right)^{16}$.

A Figura 6-B apresenta os voltamogramas cíclicos em solução eletrolítica para a amostra incubada em solução A do meio "T\&K", com microrganismo, após os tempos de incubação de 2, 7 e 14 dias. Após os primeiros dias de incubação, observou-se dois picos anódicos correspondentes à oxidação do enxofre $\left(\mathrm{A}_{2}\right)$ e do ferro $\left(\mathrm{A}_{3}\right)$. Após o $14^{\circ}$ dia ocorreu uma diminuição do pico de oxidação do enxofre e do ferro, devido ao consumo destes elementos pelo T. ferrooxidans, como conseqüência de sua intensa atividade metabólica. O pico de cobre $\left(\mathrm{A}_{1}\right)$ apresentou-se praticamente igual ao ensaio sem microrganismo (Figura 6-A).

Na parte catódica, observou-se uma diminuição do pico de redução do enxofre $\left(\mathrm{B}_{1}\right)$ após o $14^{\circ}$ dia, o qual pode estar relacionado com o consumo do enxofre elementar pela bactéria, diminuindo assim, a concentração de enxofre na superfície metálica e a transformação biológica de enxofre em $\mathrm{H}_{2} \mathrm{~S}$.

A Figura 6-C apresenta os voltamogramas cíclicos em solução eletrolítica para a amostra incubada em meio "T\&K" completo, ou seja, com adição da fonte energética de $\mathrm{Fe}^{2+}$, sem microrganismo, após 2, 7 e 14 dias de incubação. Os picos de oxidação do cobre $\left(\mathrm{A}_{1}\right)$ e enxofre $\left(\mathrm{A}_{2}\right)$ apresentaram-se praticamente iguais aos picos obtidos para a amostra sem $\mathrm{Fe}^{2+}$, nos primeiros 7 dias de incubação. Após o $14^{\circ}$ dia observou-se o aparecimento de um pico de oxidação de $\mathrm{Fe}^{2+}$ para $\mathrm{Fe}^{3+}\left(\mathrm{A}_{3}\right)$ em virtude da heterogeneidade da amostra. $\mathrm{O}$ pico $\left(\mathrm{B}_{1}\right)$, região catódica, apresentou-se de forma semelhante à $\mathrm{Fi}$ gura 6-A.

A Figura 6-D apresenta os voltamogramas cíclicos em solução eletrolítica para a amostra em meio "T\&K"completo na presença de microrganismo, após 2, 7 e 14 dias de incubação. Após o $2^{\circ}$ dia de incubação, houve o aparecimento de picos anódicos bastante pronunciados de cobre $\left(\mathrm{A}_{1}\right)$ e enxofre $\left(\mathrm{A}_{2}\right)$, sem o aparecimento de um pico de oxidação para o ferro. Este fenômeno pode ser explicado por estar ocorrendo uma oxidação indireta da covelita pelo $\mathrm{Fe}^{3+}$ produzido através da oxidação biológica do $\mathrm{Fe}^{2+}$ presente no meio. Houve então, um processo corrosivo muito acentuado, por isso picos pronunciados de cobre $\left(\mathrm{A}_{1}\right)$. $\mathrm{O}$ pico $\left(\mathrm{A}_{2}\right)$ se deve à formação de uma camada protetora de enxofre que é formada na superfície como produto dessa dissolução indireta. No $7^{\circ}$ dia, ocorreu uma diminuição 

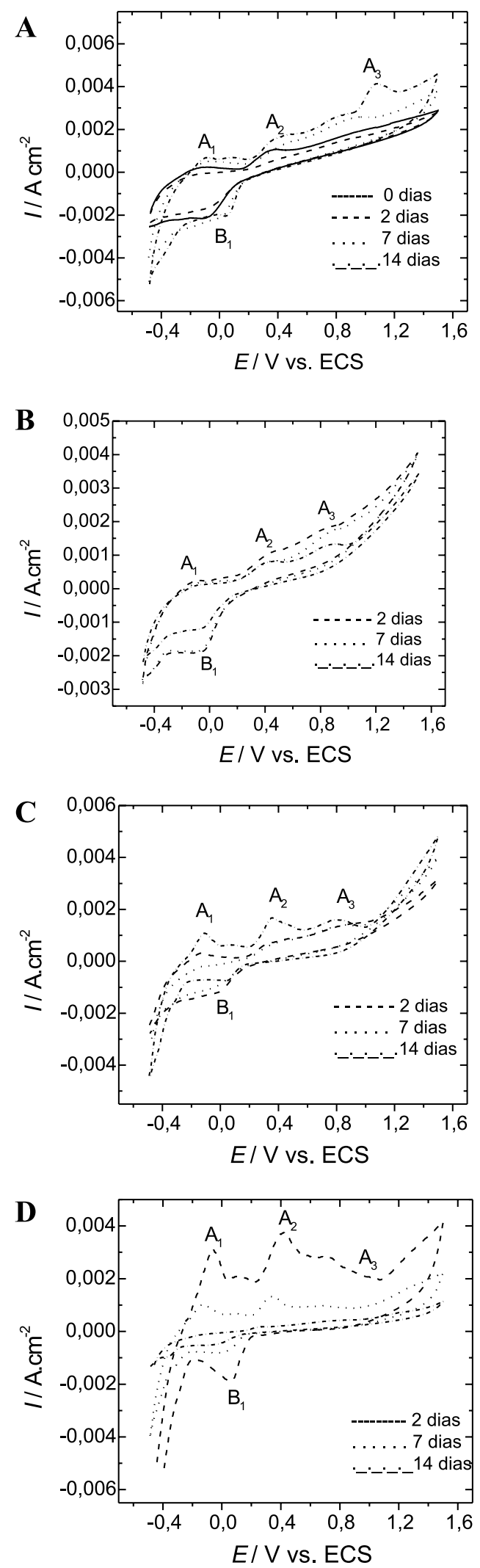

Figura 6. Voltamogramas cíclicos para as amostras de covelita em solução eletrolítica. A. amostra em solução A do meio " $T \& K$ " sem microrganismo após $0,2,7$ e 14 dias de incubação. B. amostra em solução A do meio "T\&K" com microrganismo após 2, 7 e 14 dias de incubação. C. amostra em meio " $T \& K$ " completo sem microrganismo após 2,7 e 14 dias de incubação. D. amostra em meio "T\&K" completo com microrganismo após 2, 7 e 14 dias de incubação. $v=0,025 \mathrm{~V} \mathrm{~s}^{-1}$. do pico $\left(\mathrm{A}_{2}\right)$, até que, no $14^{\circ}$ dia não se observavam mais picos de oxidação, provavelmente devido a adesão e crescimento da bactéria sobre a superfície do material. Na região catódica, houve também uma diminuição do pico $\left(\mathrm{B}_{1}\right)$, pois o processo entrou em uma fase que pode ser considerada estacionária.

\section{Análise Química da Solução}

A Tabela 2 apresenta a análise química do teor de cobre no meio de cultura após 2, 7 e 14 dias de incubação.

Tabela 2. Concentração de cobre em meio de cultura

\begin{tabular}{ccccc}
\hline $\begin{array}{c}\text { Tempo de } \\
\text { incubação }\end{array}$ & \multicolumn{4}{c}{ Concentração de cobre $\left(\mathrm{g} \mathrm{L}^{-1}\right)$} \\
\hline Dias & $\begin{array}{c}\text { Controle } \\
\text { sem Fe }^{2+}\end{array}$ & $\begin{array}{c}\text { Controle } \\
\text { com Fe }^{2+}\end{array}$ & $\begin{array}{c}\text { Inoculado } \\
\text { sem Fe }\end{array}$ & $\begin{array}{c}\text { Inoculado } \\
\text { com Fe }\end{array}$ \\
\hline 2 & 0,187 & 0,306 & 0,360 & 1,022 \\
7 & 0,426 & 1,010 & 0,243 & 3,594 \\
14 & 2,670 & 1,151 & 1,092 & 9,920 \\
\hline
\end{tabular}

\section{CONCLUSÃO}

As análises empregando-se DRX e MEV demonstraram que a amostra mineral estudada é heterogênea com vários constituintes como: covelita-CuS, pirita-FeS $\mathrm{S}_{2}$ e uma espécie de pirita que contem níquel em sua composição, além de apresentar uma superfície com muitas irregularidades.

Os ensaios eletroquímicos de potencial de circuito aberto com o tempo, sem a presença de microrganismo, mostraram que é formada uma camada de enxofre naturalmente sobre a superfície do material, com uma contínua formação e rompimento desta camada nos primeiros dias de incubação. Na presença do microrganismo ocorre um rompimento da camada de enxofre, devido a sua atividade metabólica, diminuindo consideravelmente o potencial. Assim, a ação microbiológica sobre a camada de enxofre acelera a reação de oxidação do mineral.

Empregando-se a voltametria cíclica observou-se que o processo corrosivo é facilitado na presença de microrganismo e $\mathrm{Fe}^{2+}$. Essa corrosão foi demonstrada pela análise química de cobre em solução, o qual apresentou uma concentração significativamente maior na presença desses .

As técnicas eletroquímicas se mostraram uma ferramenta eficiente no acompanhamento da biodissolução do cobre e na otimização desse processo em escala industrial, pois essas técnicas permitem analisar os fenômenos que ocorrem no processo de lixiviação bacteriana.

\section{AGRADECIMENTOS}

Agradecimentos são devidos à FAPESP, Fundação Andes, CAPES (bolsa de mestrado em Biotecnologia, Christiane M. Teixeira), CNPq (bolsa de produtividade em pesquisa, Dr. Oswaldo Garcia Jr), ao Dr. Paulo César Duarte no auxílio das interpretações dos DRXs e ao Laboratório de Poços de Caldas - CNEN (Wilson C. Costa) pelas análises químicas.

\section{REFERÊNCIAS}

1. Johnson, D. B.; In: R. Amils \& A. Ballester (Eds.), Proc. International Biohydrometallurgy Symposium, Madrid, Espanha; Elsevier, Amsterdan, ISBN: 0444501932 (A \& B) 1999, part A, p 645. 
2. Lindstron, E. B.; Gunneriusson, E.; Tuovinen, O. H.; Crit. Rev. Biotechnol. 1992, 12, 133.

3. Hackl, R. P.; Biological Mineralogical Interactions; Ottawa, 1997, 25, 143.

4. Evangelou, V. P.; Zhang, Y. L.; Crit. Rev. Environ. Sci. Technol. 1995, 25, 141.

5. Sullivan, J. D.; U. S. Departament of Commerce, Bureau of Mines, Technical paper; Washington, D.C, 1930

6. Corrans, I. J.; Harris, B., Ralph; B. J.; J. S. Afr. Inst. M. Metal. 1972, 72, 221.

7. Monteiro, V. F.; Dissertação de Mestrado; UNESP, Araraquara, SP 1998.

8. Lawrence, J. R.; Kwong, Y. T. J.; Swerhone, G. D. W.; Can. J. Microbiol. 1997, 43, 178 .
9. Mehta, A. P.; Murr, L. E.; Biotechnol. Bioeng. 1982, 24, 919.

10. Mustin, C.; Berthelin, J.; Marion, P.; Donato, P.; Appl.Environ. Microbiol. 1992, 58, 1175.

11. Garcia Jr., O.; Microbiol. Rev. 1991, 20, 1

12. Tuovinen, O. H.; Kelly, D.P.; Arch. Microbiol. 1973, 88, 285.

13. Barron, J. L.; Lueking, D. R.; Appl.Environ. Microbiol. 1990, 56, 2801

14. Brett, A. M. O.; Brett, C. M. A.; Eletroquímica: princípios, métodos e aplicações, Oxford: Oxford University Press, 1993, p 191.

15. Padilha, A. F.; Ambrósio Fo , F.; Técnicas de Análise Microestrutural; São Paulo, Ed.Hemus Editora Ltda, 1985.

16. Teixeira, C. M.; Dissertação de Mestrado; UNESP, Araraquara, SP 2000. 